\title{
Community outbreak of group B meningococcal disease in southwest France - December 2008 to September 2009
}

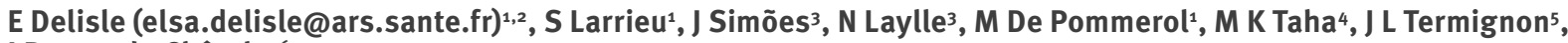

I Parent du Châtelet ${ }^{6}$

1. Branch of the Institut de Veille Sanitaire in the Région Aquitaine (InVS, French Institute for Public Health Surveillance), Bordeaux, France

2. Programme de Formation à l'Epidémiologie de Terrain (PROFET, French Training Program in Field Epidemiology), Institut de Veille Sanitaire (InVS, French Institute for Public Health Surveillance), Saint-Maurice, France

3. Health District Office, Mont-de-Marsan, France

4. National Reference Centre for Meningococci, Institut Pasteur, Paris, France

5. French Agency of Health, Ministry of Health, Paris, France

6. Department of Infectious Diseases, Institut de Veille Sanitaire (InVS, French Institute for Public Health Surveillance), Saint-Maurice, France

Delisle E, Larrieu S, Simões J, Laylle N, De Pommerol M, Taha MK, Termignon JL, Parent du Châtelet I. Community outbreak of group B meningococcal disease in southwest France - December 2008 to September 2009. Euro Surveill. 2010;15(37):pii=19665. Available online: http://www.eurosurveillance.org/ViewArticle. aspx?Articleld $=19665$

Between December 2008 and September 2009, 11 cases of invasive meningococcal disease (IMD) group $B$ were reported in a $20 \mathrm{~km}$ diameter area in the Département Landes, France. Two of them presented with purpura fulminans and one of them died. The strain responsible for this community outbreak was of the clonal complex ST-269.The incidence rate for IMD group B was 3 per 100,000 inhabitants in Landes from week 40 in 2008 to week 40 in 2009; it was the highest in France during that period. The number of cases observed was significantly higher than expected, especially in young adults (standardised incidence ratio: $23.5, p<0.001$ ). A nightclub located in the $20 \mathrm{~km}$ diameter area was a possible place of transmission and a prophylaxis recommended for the staff members helped in decreasing the transmission. However, several cases notified later suggested that the bacteria circulated during several months through healthy carriers in the community. This situation prompted increased surveillance of IMD in Landes and medical practitioners were asked to remain vigilant because of the possible emergence of new cases within the following months.

\section{Introduction}

Invasive meningococcal disease (IMD) is a severe infection that can create concerns in the population. The disease is notifiable in France [1] and following each notification, control measures are implemented by the concerned health district office in order to prevent secondary cases. Outbreaks are rare and when they occur, the French Institute for Public Health (InVS) may intervene to carry out an epidemiological investigation.

In December 2008, one case of IMD group B was reported to a health district office in the Département
Landes (population 375,000), Aquitaine region. One month later, four more cases of IMD group B were reported to the same health district office within one week. This number was unusually high; the total number of cases notified to this department had been seven in 2007 and four in 2006. Furthermore, all five cases were living within a limited area of the Département.

An epidemiological investigation was therefore initiated in January 2009 by the local InVS team in collaboration with the health district department of Landes. The aims were to describe characteristics of the cases and their potential epidemiological links, to identify the source of infection and to suggest control and preventive measures.

\section{Methods}

Cases were reported to the health district department by hospital practitioners through the French surveillance system of IMD. Since 2006, the case definition of IMD in France has been the following [1]:

- $\quad$ Either a patient laboratory-confirmed by at least one of the following methods:

- detection of Neisseria meningitidis by culture and/ or detection of $N$. meningitidis nucleic acid by PCR from any sterile site;

- detection of Gram-negative diplococci in cerebrospinal fluid (CSF);

- SF findings compatible with bacterial meningitis together with detection of $N$. meningitidis antigens in blood, urine or CSF;

- Or a patient with clinical presentation suggestive of IMD (CSF findings compatible with bacterial menin- 
gitis together with a petechial rash and /or purpura fulminans (haemorrhagic septic shock).

All cases of IMD group B notified from December 2008 onwards who were living, working or going to school in the Département Landes were interviewed by the health district department or by epidemiologists of

\section{FIGURE 1}

Cases of invasive meningococcal disease group B by month of notification, December 2008-September 2009, Landes, France $(\mathrm{N}=11)$

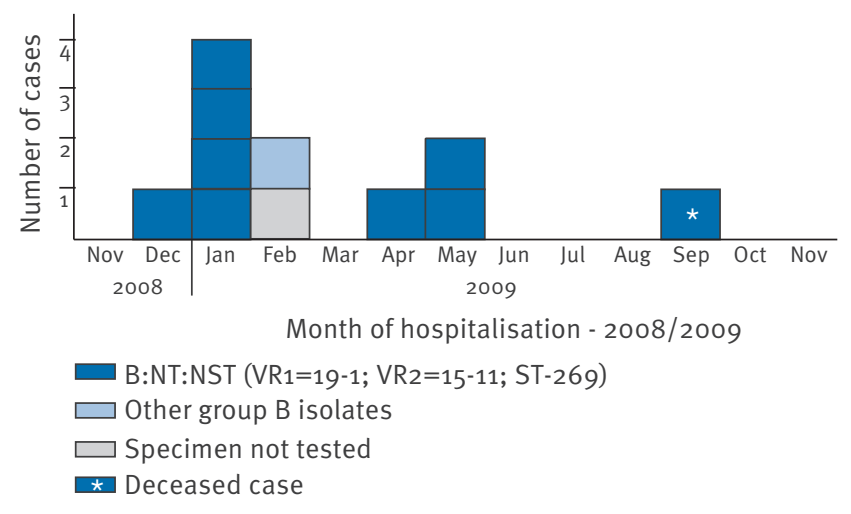

Source : French Institute for Public Health, 2009. the local InVS team. Information on sociodemographic characteristics, medical history were collected, as well as on activities within the 10 days before symptoms onset (work or school place, travel, meetings, celebrations and any other occasion involving close contacts).

Specimens from each case were sent to the national reference centre for meningococci (CNR) for complete typing that consists of phenotyping (serogroup:sero type:serosubtype) and genotyping using multilocus sequence typing (MLST) [2] as well as typing of porA.

The study area was defined as the smallest area covering all cases occurred. Incidence of IMD by age group was estimated in this area and in the Département Landes and compared with the incidence in the rest of France. The number of expected cases in Landes was estimated by age group using incidence rates of IMD group B in the rest of France (indirect standardisation). Standardised incidence ratios (SIR, ratio of observed to expected cases) was calculated for each group.

\section{Results}

Outbreak description

A total of 11 cases of IMD group B were notified in Landes between December 2008 and September 2009 (Figure 1). The cases were localised in an area of $20 \mathrm{~km}$

\section{FIGURE 2}

Relations between cases of invasive meningococcal disease group B, Landes, France, December 2008-September 2009 $(\mathrm{N}=11)$

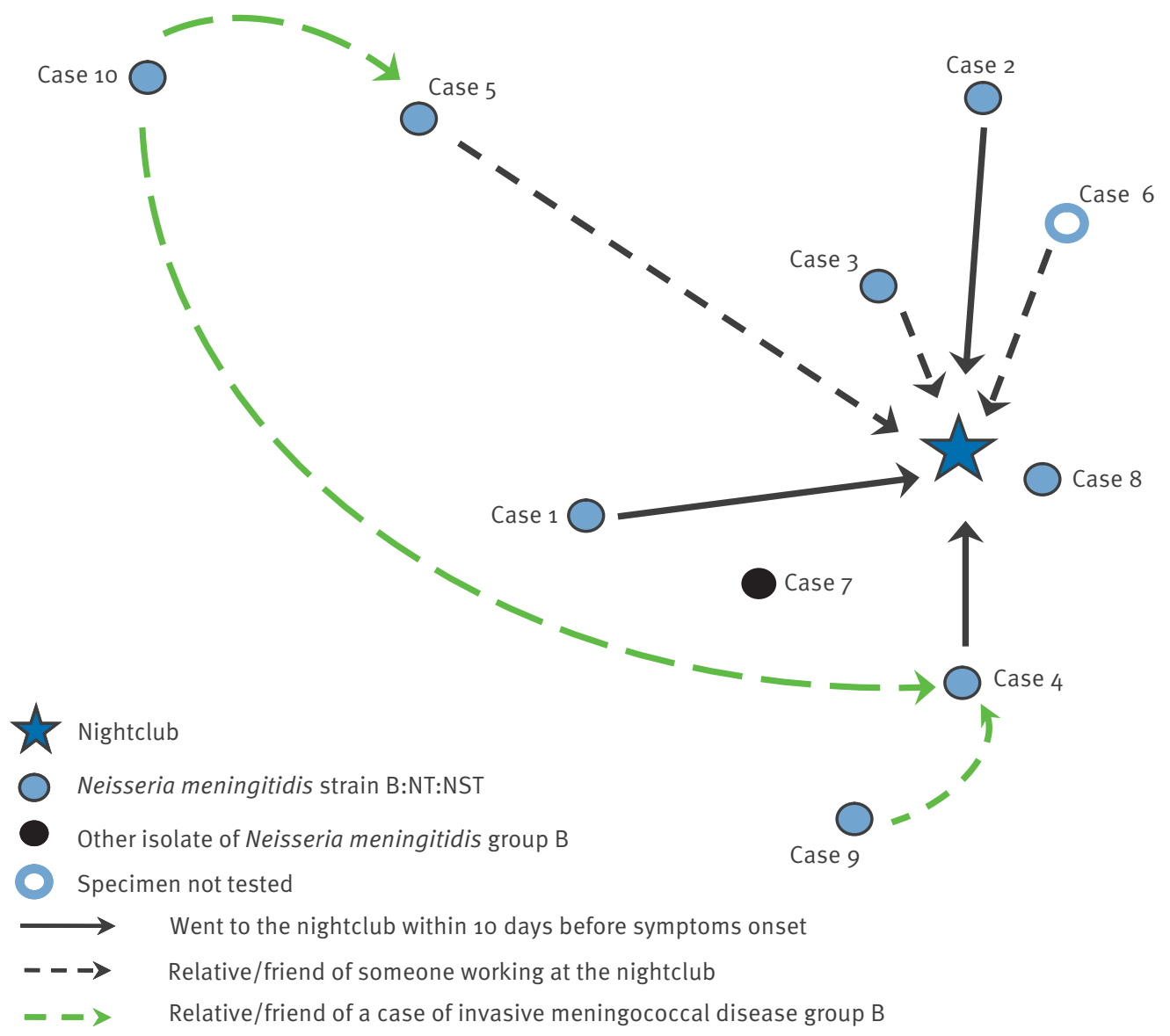


diameter (population 125,000) near the city of Dax, in the south west of the Département Landes.

The age range of the cases was between seven months and 47 years (median age: 18 years), six cases were male. Two cases presented with purpura fulminans and one of them (a four-year-old child) died the day after hospitalisation. The nine other cases fully recovered a few days after their admission to hospital.

Eight of the 11 cases lived in the Dax area permanently, two during week-ends and holidays only, and one only during the week. No case of IMD was reported in the rest of the Département or in the neighbouring Département (Pyrénées-Atlantiques) between December 2008 and September 2009.

\section{Relations between cases}

Epidemiological investigations could not identify a common link among the first eight cases. However, three of them went to the same nightclub on different nights within 10 days before symptoms onset and three others had relatives or friends working at the nightclub (Figure 2). The ninth and tenth case (onset in May 2009) were friend or family of respectively one and two previous cases. No link with other cases was found for the last case that occurred in September 2009. No other common place or more confined community (school, social group, etc.) was identified.

\section{Incidence rates}

The incidence rate for group B IMD was 3 per 100,000 inhabitants in the Département Landes and 8.9 in the affected area of Dax, whereas the incidence in the same time period at national level was 0.6 per 100,000 (Table). The incidence in Landes was the highest observed in any French Département in the period under investigation. For all age groups, the observed number of cases was 4.5 times higher than the expected number of cases ( $p<0.001)$.

The age distribution of the cases in Landes differed from that observed for the whole of France in that four
(36\%) of the Landes cases were between 20 and 24 years of age, whereas at the national level this age group only represented $10 \%$ in 2008 . The incidence rate was therefore particularly high in this age group $(25.1 / 100,000)$ and the number of cases observed was 23.5 times higher than expected ( $p<0.001$ ). A similar but less pronounced trend was observed in the group of 15-19-year-olds with the number of observed cases nearly seven times higher than the number of expected cases $(p=0.08)$ (Table).

\section{Laboratory investigation}

All 11 cases were laboratory-confirmed as infected with $N$. meningitidis serogroup $B$ and further analyses were performed by the CNR on 10 specimens (testing was technically not possible for one specimen). The strains were not typable and not serosubtypable (B:NT:NST). PorA sequencing revealed identical variable regions (VR) among most of the tested isolates (VR1=19-1; VR2 $=15-11$ ) (9 of 10 strains tested) and MLST analysis clustered these isolates in the clonal complex (CC) ST-269. All the tested isolates were susceptible to the antibiotics that are currently used in treatment and prophylaxis (rifampicin, cefotaxime, penicillin G, ciprofloxacin).

\section{Control measures}

In order to prevent further spread of the disease and according to the national recommendations and policy [1], individual control measures were implemented for each case by the local health department, including post-exposure chemoprophylaxis for all close contacts of cases.

Furthermore, prophylaxis with rifampicin was recommended for the nightclub staff (10 people) at the end of February 2009, after the occurrence of several cases who had a direct or indirect link with this venue. All general practitioners and acute care hospital practitioners were sent an email describing the outbreak. They were alerted to be vigilant and notification was encouraged. Information on early symptoms of IMD

\section{TABLE}

Cases of invasive meningococcal disease group B and incidence rates by age group for the Département Landes (52 weeks: from week 40 in 2008 to week 40 in 2009) and the rest of France (year 2008)

\begin{tabular}{|c|c|c|c|c|c|c|c|c|c|c|}
\hline \multirow[b]{2}{*}{$\begin{array}{l}\text { Age groups } \\
\text { (years) }\end{array}$} & \multicolumn{3}{|c|}{$\begin{array}{l}\text { Incidence rate in the Département } \\
\text { Landes }\end{array}$} & \multicolumn{3}{|c|}{ Incidence rate in the rest of France ${ }^{a}$} & \multicolumn{4}{|c|}{$\begin{array}{l}\text { Estimation of the risk excess } \\
\text { in the Département Landes }\end{array}$} \\
\hline & $\begin{array}{c}\text { Number of } \\
\text { cases }\end{array}$ & $(\%)$ & $\begin{array}{c}\text { Incidence per } \\
100,000\end{array}$ & Number of cases & (\%) & $\begin{array}{l}\text { Incidence per } \\
100,000\end{array}$ & $\begin{array}{c}\text { Number of } \\
\text { cases }\end{array}$ & $\mathrm{SIR}^{\mathrm{b}}$ & $\mathrm{p}^{\mathrm{c}}$ & $\begin{array}{l}\text { Confidence } \\
\text { interval }\end{array}$ \\
\hline$<5$ & 3 & 27 & $15 \cdot 5$ & 189 & 46 & 4.8 & 0.94 & 3.2 & 0.14 & $0.6-9.2$ \\
\hline $5-14$ & 1 & 9 & 2.4 & 43 & 10 & 0.5 & 0.23 & 4.3 & 0.41 & $0.1-24.2$ \\
\hline $15-19$ & 2 & 18 & 10.0 & 63 & 15 & 1.5 & 0.30 & 6.7 & 0.08 & $0.7-24.1$ \\
\hline $20-24$ & 4 & 36 & 25.1 & 42 & 10 & 1.0 & 0.17 & 23.5 & $<0.001$ & $6.3-60.2$ \\
\hline$\geq 25$ & 1 & 9 & 0.4 & 77 & 19 & 0.2 & 0.48 & 2.1 & 0.75 & $0.0-11.6$ \\
\hline Total & 11 & 100 & 3.0 & 414 & 100 & 0.6 & 2.41 & 4.6 & $<0.001$ & $2.3-8.2$ \\
\hline
\end{tabular}

a excluding Landes.

b Standardised incidence ratio : ratio of observed to expected cases.

c $p$-value number of observed cases $\neq$ number of expected cases.

Source: French Institute for Public Health, 2009. 
was communicated to the general population through the local press.

\section{Discussion and conclusion}

Between December 2008 and September 2009, an outbreak of group B IMD occurred in the French Département of Landes. It was caused by one clone of $N$. meningitidis belonging to the CC ST-269. The cases were concentrated in a limited geographical area, with an unusually high incidence rate compared with the preceding years: since the year 2000 , the mean annual incidence rate of group B IMD has been 1.4 per 100,000 inhabitants in Landes (data from the French surveillance system of IMD [3])

The investigation suggested that the nightclub was one place of transmission of the disease and, as no cases were notified for the two months following the implementation of the recommendation (Case 8 occurred at the end of April), that the prophylaxis recommended for the staff members of the nightclub in February helped to stop the transmission.

The appearance of new cases that were not related to the nightclub but to previous cases, suggested that bacteria had circulated during several months through healthy carriers. Indeed, it was shown that at any time, approximately $10 \%$ of the general population were carrying $N$. meningitidis in the nasopharynx and that the carriage rate was $30 \%$ in teenagers and young adults [4]. Moreover, the time intervals between the occurrence of cases who knew each other were not consistent with a direct transmission.

In this outbreak, the age group of 15-24-year-olds seems to have been particularly affected. Teenagers and young adults have been shown previously to be at higher risk during IMD outbreaks [5-7]. This could be due to lifestyle since an active social life can increase the risk of infection when bacteria circulate in the population. Moreover, as nightclubs are mainly frequented by teenagers and young adults, high incidence among this group may also be a consequence of the nightclub as a possible place of transmission.

However, a shift in the age distribution of meningococcal disease towards higher age groups ( $\geq 20$ years-old) can be observed during outbreaks and epidemics following the introduction of new clone [8].

Since 2007 there has been an increase of CC ST-269 isolates in France: $10 \%$ of the strains responsible for IMD analysed by the CNR in 2009 belonged to this CC (5\% in the last ten years). These isolates may differ in virulence, as has been observed for the common CCs ST-32 and ST 41/44 [9], and seem to be highly transmissible.

Since no universal vaccine against serogroup B exists, the relevance of implementing a mass chemoprophylaxis was widely discussed by local authorities and national experts on IMD infections. This strategy had been implemented twice before in France to control IMD group B outbreaks confined to small areas $[10,11]$. However, it was finally not recommended in the Landes department because of the dynamics of the outbreak: indeed, cases were spread over time and space and were part of an open population. Such a recommendation would have had a limited effect because of a high risk that individuals not targeted by the prophylaxis would rapidly reintroduce the bacteria in the treated population [12]. In a larger epidemic of group B IMD that recently occurred in another French Département, a massive preventive intervention could be launched because an unlicensed outer membrane vesicle vaccine was available against the strain responsible for the outbreak [5].

General and acute care hospital practitioners were asked to remain vigilant in case new cases should emerge in the following months. No new case was reported until the end of 2009 , but the increased surveillance implemented during this outbreak showed that the bacteria are still present in the Département Landes in 2010. Indeed, two cases of group B meningococcal disease infected with $N$. meningitidis CC ST-269 were reported in January and August 2010; one died a few days after hospitalisation. Both were living in the Dax area.

\section{Acknowledgements}

We would like to thank C.Castor and Dr M.Charron (Cire Aquitaine, French Institute for Public Health Surveillance) for their valuable technical and scientific support and Dr B.Pedalino (French Institute for Public Health Surveillance) for revising the manuscript.

This work should be attributed to the Cellule de l'InVS en région (Cire) Aquitaine, French Institute for Public Health.

\section{References}

1. French Ministry of Health and Sports. Circulaire $\mathrm{DGS} / 5 \mathrm{C} / 2006 / 458$ du 23 octobre 2006 relative à la prophylaxie des infections invasives à méningocoque. [National recommendations and policy regarding prophylaxis of invasive meningococcal diseases (DGS/5C/2006/458, 23 October 2006]. Paris: 2006 . French. Available from: http://www.infectiologie. com/site/medias/_documents/officiels/meningo_circ_2006. pdf

2. Maiden MC, Bygraves JA, Feil E, Morelli G, Russell JE, Urwin $\mathrm{R}$ et al. Multilocus sequence typing: a portable approach to the identification of clones within populations of pathogenic microorganisms. Proc Natl Acad Sci USA. 1998;95:3140-5.

3. French Institute for Public Health Surveillance (Institut de Veille Sanitaire, InVS). [Internet]. Données épidémiologiques annuelles 1995-2008. [Annual epidemiological data 19952008]. Paris; 2009. French. Available from: www.invs.sante.fr/ surveillance/iim/default.htm

4. Yazdankhah SP, Caugant DA. Neisseria meningitidis: an overview of the carriage state. J Med Microbiol. 2004;53(Pt 9):821-32.

5. Rouaud P, Perrocheau A, Taha MK, Sesboué C, Forgues $A M$, Parent du Châtelet l et al. Prolonged outbreak of $B$ meningococcal disease in the Seine-Maritime department, France, January 2003 to June 2005 . Euro Surveill. 2006;11(7):178-81. pii: Available from: http://www. eurosurveillance.org/ViewArticle.aspx?Articleld=635

6. Tyrrell GJ, Chui L, Johnson M, Chang N, Rennie RP, Talbot JA; Edmonton Meningococcal Study Group. Outbreak of Neisseria meningitidis, Edmonton, Alberta, Canada. Emerg Infect Dis. 2002;8(5):519-21. 
7. Cartwright KA, Stuart JM, Noah ND. An outbreak of meningococcal disease in Gloucestershire. Lancet. 1986;2(8506):558-61.

8. Peltola H, Kataja JM, Mäkelä PH. Shift in the age-distribution of meningococcal disease as predictor of an epidemic? Lancet. 1982;2(8298):595-7.

9. Zarantonelli ML, Lancellotti M, Deghmane AE, Giorgini D, Hong $E$, et al. Hyperinvasive genotypes of Neisseria meningitidis in France. Clin Microbiol Infect. 2008;14(5):467-72.

10. Perrocheau A. Outbreak of group B meningococcal disease in France prompted community chemoprophylaxis. Euro Surveill. 2000;4(13): pii=1631. Available from: www.eurosurveillance. org/ViewArticle.aspx?Articleld=1631

11. Termignon JL, Deshayes F, Kermarec F, Bilo de Bernardi P, Alsibai S. Décision et mise en oeuvre d'une chimioprophylaxie élargie en population générale dans un contexte de cas groupés d'infections invasives à méningocoques de groupe B: l'expérience de Metz-Borny, France, 2003. [Implementation of a mass chemoprophylaxis in the general population following an outbreak of group B meningococcal disease: the Metz-Borny case study, France, 2003]. French. Available from : http://www. invs.sante.fr/publications/2005/jvs_2005/veille_sanitaire recherche.pdf

12. Katz LH, Zelazny A, Scharf S, Hourvitz A, Asor N, Arbeli $Y$ et al. Mass antibiotic treatment to stop an outbreak of meningococcal disease: a molecular analysis. Clin Microbiol Infect. 2007;13(9):943-6. 